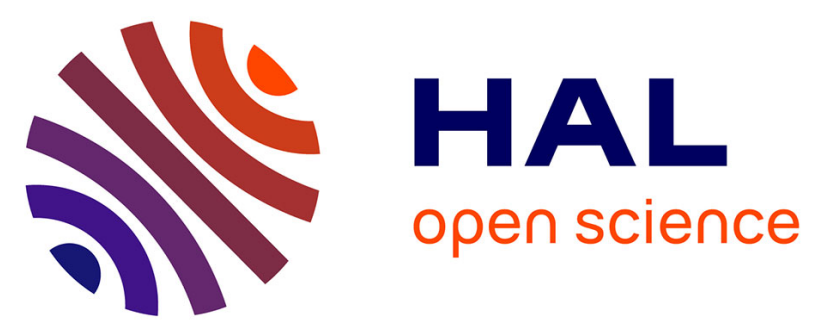

\title{
The function-dominance correlation drives the direction and strength of biodiversity-ecosystem functioning relationships
}

Michael S. Crawford, Kathryn E. Barry, Adam T Clark, Caroline E Farrior, Jes Hines, Emma Ladouceur, Jeremy W Lichstein, Isabelle Maréchaux, Felix May, Akira S Mori, et al.

\section{To cite this version:}

Michael S. Crawford, Kathryn E. Barry, Adam T Clark, Caroline E Farrior, Jes Hines, et al.. The function-dominance correlation drives the direction and strength of biodiversity-ecosystem functioning relationships. Ecology Letters, 2021, 24 (9), pp.1762-1775. 10.1111/ele.13776 . hal-03269454

\section{HAL Id: hal-03269454 \\ https://hal.inrae.fr/hal-03269454}

Submitted on 24 Jun 2021

HAL is a multi-disciplinary open access archive for the deposit and dissemination of scientific research documents, whether they are published or not. The documents may come from teaching and research institutions in France or abroad, or from public or private research centers.
L'archive ouverte pluridisciplinaire HAL, est destinée au dépôt et à la diffusion de documents scientifiques de niveau recherche, publiés ou non, émanant des établissements d'enseignement et de recherche français ou étrangers, des laboratoires publics ou privés. 


\title{
The function-dominance correlation drives the direction and strength of biodiversity-ecosystem functioning relationships (1)
}

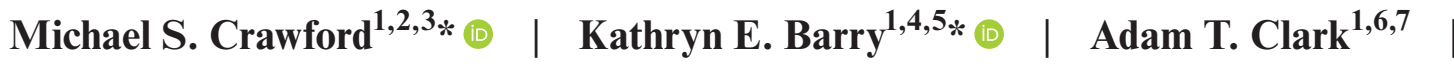

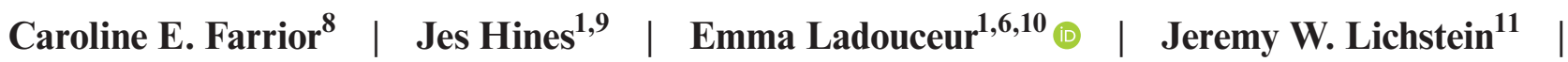 \\ Isabelle Maréchaux $^{12,13}$ | Felix May ${ }^{14}$ | Akira S. Mori ${ }^{15}$ | Björn Reineking ${ }^{16}$ \\ Lindsay A. Turnbull ${ }^{17}$ @ | Christian Wirth ${ }^{1,4,16,18}$ | Nadja Rüger ${ }^{1,2,19}{ }^{\infty}$ \\ ${ }^{1}$ German Centre for Integrative Biodiversity Research (iDiv) Halle-Jena-Leipzig, Leipzig, Germany \\ ${ }^{2}$ Department of Economics, Institute of Empirical Economic Research, University of Leipzig, Leipzig, Germany \\ ${ }^{3}$ Department of Land-Use Management, Potsdam Institute for Climate Impact Research (PIK), Potsdam, Germany \\ ${ }^{4}$ Institute of Biology, University of Leipzig, Leipzig, Germany \\ ${ }^{5}$ Ecology and Biodiversity Group, Department of Biology, Utrecht University, Utrecht, Netherlands \\ ${ }^{6}$ Department of Physiological Diversity, Helmholtz Centre for Environmental Research (UFZ), Leipzig, Germany \\ ${ }^{7}$ Institute of Biology, University of Graz, Graz, Austria \\ ${ }^{8}$ Department of Integrative Biology, University of Texas at Austin, Austin, Texas, USA \\ ${ }^{9}$ University of Leipzig, Leipzig, Germany \\ ${ }^{10}$ Biodiversity Synthesis, Institute of Computer Science, Martin Luther University Halle-Wittenberg, Halle, Germany \\ ${ }^{11}$ Department of Biology, University of Florida, Gainesville, Florida, USA \\ ${ }^{12}$ AMAP, University of Montpellier, CIRAD, CNRS, INRAE, Montpellier, IRD, France \\ ${ }^{13}$ Laboratoire Évolution et Diversité Biologique, UMR 5174 (CNRS/IRD/UPS), Toulouse Cedex, France \\ ${ }^{14}$ Institute of Biology, Freie Universität Berlin, Gartenhaus, Berlin, Germany \\ ${ }^{15}$ Graduate School of Environment and Information Sciences, Yokohama National University, Yokohama, Japan \\ ${ }^{16}$ University of Grenoble Alpes, INRAE, LESSEM, Grenoble, France \\ ${ }^{17}$ Department of Plant Sciences, University of Oxford, Oxford, UK \\ ${ }^{18}$ Max-Planck-Institute for Biogeochemistry, Jena, Germany \\ ${ }^{19}$ Smithsonian Tropical Research Institute, Balboa, Ancón, Panama
}

\section{Correspondence}

Michael S. Crawford, Transformation Pathways, Potsdam Institute for Climate Impact Research (PIK), Telegrafenberg, Potsdam 14412, Germany.

Email: mscrawfor@gmail.com

\section{Funding information}

Deutsche Forschungsgemeinschaft, Grant/ Award Number: FZT 118, RU 1536/3-1 and 202548816; German Centre for Integrative Biodiversity Research (iDiv), Grant/Award Number: 34600967, 34600900, 34600966 and 34600970; Agence National de la Recherche, Grant/Award Number: ANR10-LABX-0041 and ANR-10-LABX-25-01

Editor: Xavier Morin

\begin{abstract}
Community composition is a primary determinant of how biodiversity change influences ecosystem functioning and, therefore, the relationship between biodiversity and ecosystem functioning (BEF). We examine the consequences of community composition across six structurally realistic plant community models. We find that a positive correlation between species' functioning in monoculture versus their dominance in mixture with regard to a specific function (the "function-dominance correlation") generates a positive relationship between realised diversity and ecosystem functioning across species richness treatments. However, because realised diversity declines when few species dominate, a positive function-dominance correlation generates a negative relationship between realised diversity and ecosystem
\end{abstract}

*Joint first authors.

This is an open access article under the terms of the Creative Commons Attribution License, which permits use, distribution and reproduction in any medium, provided the original work is properly cited.

(C) 2021 The Authors. Ecology Letters published by John Wiley \& Sons Ltd. 
functioning within species richness treatments. Removing seed inflow strengthens the link between the function-dominance correlation and BEF relationships across species richness treatments but weakens it within them. These results suggest that changes in species' identities in a local species pool may more strongly affect ecosystem functioning than changes in species richness.

\section{K E Y W O R D S}

coexistence, community assembly, function-dominance correlation, model intercomparison, plant diversity, productivity, seed dispersal

\section{INTRODUCTION}

Anthropogenic environmental changes have led to drastic global biodiversity loss (IPBES, 2019; MEA, 2005; Newbold et al., 2015; Tittensor et al., 2014). The rate of loss will likely accelerate in the coming decades (IPBES, 2019; Pereira et al., 2010; Pimm et al., 2014). Biodiversity experiments demonstrate that the loss of randomly selected species from controlled communities generally decreases local ecosystem functioning (Tilman et al., 2014). However, in natural systems, the effects of biodiversity change on ecosystem functioning and services are context dependent. Even within a single ecosystem type such as grasslands, there is significant divergence in the direction (negative vs. positive; Meyer et al., 2018), strength (Guerrero-Ramírez et al., 2017) and drivers (Barry et al., 2019b) of biodiversity-ecosystem functioning $(\mathrm{BEF})$ relationships. This variation is even greater across ecosystem types (Duffy et al., 2017; van der Plas, 2019). Understanding this variability is therefore of critical importance to anticipating the impacts of biodiversity change.

One likely cause of this variability is differences in local-scale processes such as species interactions, which influence community assembly and composition (Barry et al., 2019a; Holt, 2013; Wright, 2002). Depending on the nature and strength of local and regional community assembly mechanisms, variation in these processes may result in differences among BEF relationships across ecosystems and scales (Leibold et al., 2017). In particular, when comparing communities that differ greatly in species richness, those with high richness are more likely to include species that produce high levels of ecosystem functioning (e.g., biomass) through "sampling effects" (Hooper et al., 2005; Huston, 1997), leading to positive BEF relationships. Conversely, when comparing communities with similar species richness, if a few dominant species contribute disproportionately to functioning and are able to supress their competitors, then communities that include these dominant species will have low realised diversity but high functioning, leading to negative BEF relationships (Leibold et al., 2017, Figure 1a). We refer to this characteristic pattern of contrasting BEF relationships across communities as a "counter-gradient" (Figure 1). This type of counter-gradient is often associated with Simpson's paradox, which arises when observed relationships vary across different subsets of data (Simpson, 1951).

In addition to local processes related to species identity and dominance, regional processes such as seed dispersal can affect community composition by maintaining populations that would otherwise go extinct (Leibold \& Chase, 2018; Thompson \& Gonzalez, 2016). These regional-scale processes influence ecosystem functioning independently of local-scale processes (Gonzalez et al., 2020; Leibold \& Chase, 2018; Thompson et al., 2020). For example, if dispersal maintains populations of species that are poorly locally adapted, then dispersal can weaken or lead to negative, BEF relationships (Thompson et al., 2020). Alternatively, if species that contribute strongly to ecosystem functioning are maintained by dispersal, then dispersal can lead to strong positive BEF relationships (Gonzalez et al., 2009; Shanafelt et al., 2015; Thompson \& Gonzalez, 2016; Thompson et al., 2020).

Here, we consider six independently derived and validated plant community models to explore the drivers of variation in BEF relationships across local and regional scales. We subjected these six models to a unified set of simulation experiments: first, testing local effects by varying initial diversity and composition and, second, testing regional effects by simulating communities that included, or were isolated from, seed dispersal. Although plant community models have been used in the past to explore BEF relationships (Bohn \& Huth, 2017; Holzwarth et al., 2015; Maréchaux \& Chave, 2017; Morin et al., 2011), here, we consider a much wider variety of models, systems (grasslands, forests and drylands) and community assembly processes. This diversity of modelling approaches leads to a much wider range of resulting $\mathrm{BEF}$ relationships, thereby better mirroring the context dependence observed in natural systems.

We use this modelling experiment to test two hypotheses. First, we hypothesise that context dependence in BEF relationships observed across simulations can be explained primarily by correlations between species' ability to dominate in mixture ('dominance') versus their baseline capacity to contribute to ecosystem functioning in monoculture ('functioning'). We refer to this correlation as the 'function-dominance correlation'. When the 
(b) Negative function-dominance correlation

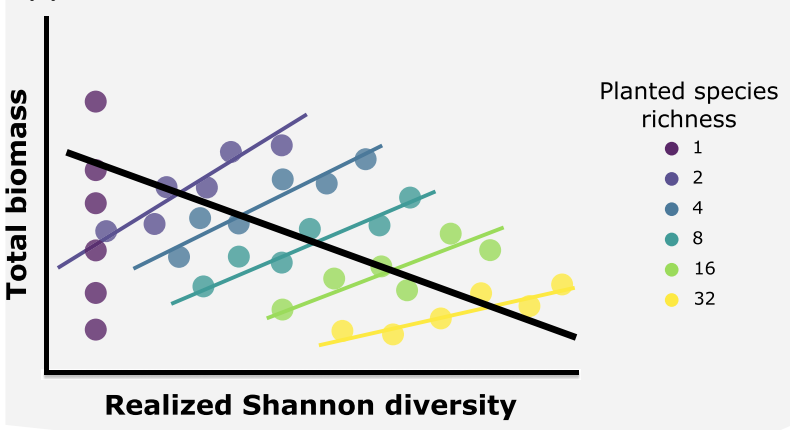

(a)

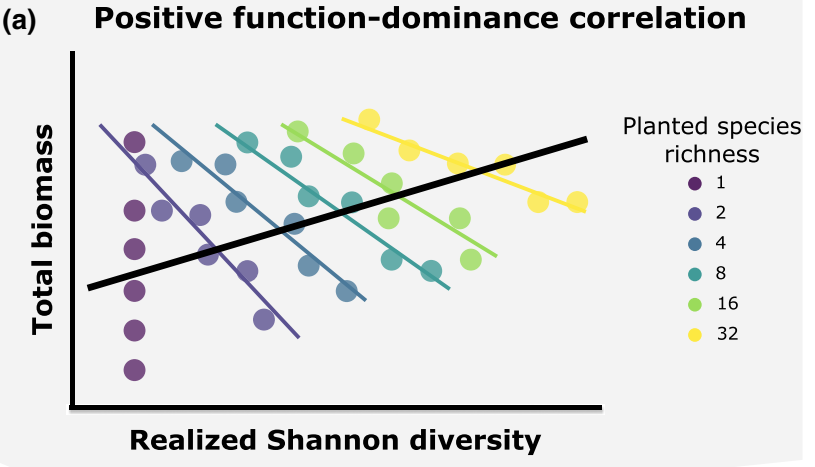

(c)

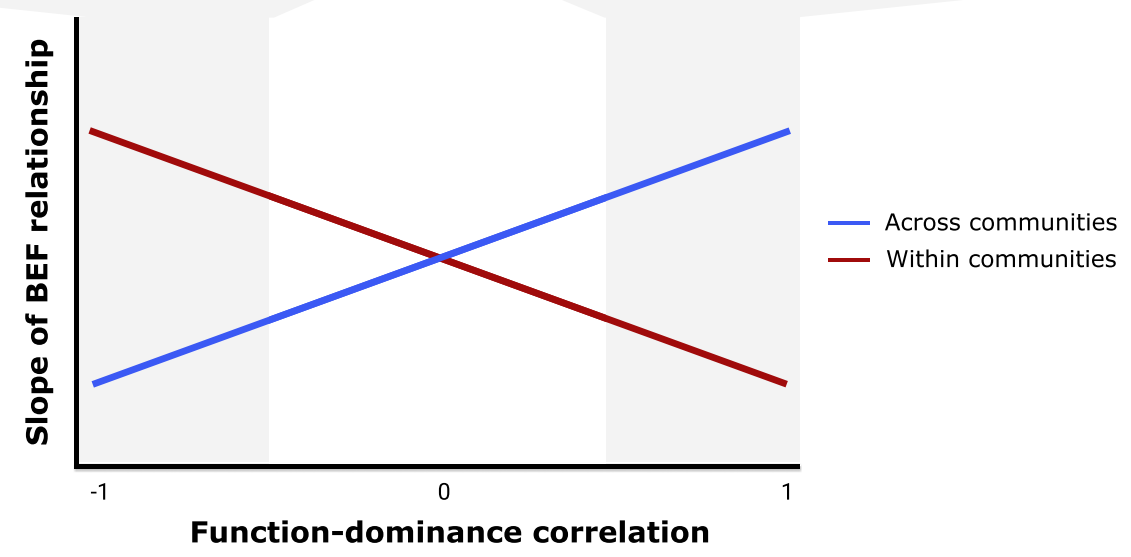

F I G URE 1 We hypothesise that the strength and direction of the relationship between the diversity of a community and its total biomass will depend on the function-dominance correlation of its species (c). Communities with a positive function-dominance correlation (a) will tend to be dominated by species that also generate significant functioning. When included in a mixture, these species will decrease biodiversity as they increase total biomass. Across species richness treatments, the likelihood of these species being incorporated into a community will increase, leading to a positive relationship between diversity and biomass. However, within species richness treatments, communities incorporating these dominant species will tend to have lower biodiversity - though more biomass - than communities in which they are absent. A negative function-dominance correlation (b) will lead to alternative diversity-biomass relationships, as they will tend to be dominated by species that provide little functioning. Across species richness treatments, this will lead to a negative relationship between diversity and biomass, as competitive - though low biomass - species are more likely to be incorporated into diverse mixtures. However, within species richness treatments, there will be a positive relationship between biomass and functioning as communities that lack these competitive species will subsequently contain higher diversity and biomass

function-dominance correlation is positive, we expect to observe positive BEF relationships across communities that differ in species richness (due to positive sampling effects) versus negative BEF relationships across communities with similar richness (due to disproportionately strong contributions by dominant species; Figure 1a). Similarly, we expect to observe the opposite relationships when the function-dominance correlation is negative (due to negative sampling effects and disproportionately weak contributions from dominant species; Figure 1b). We refer to these two different scales of expected BEF relationships as across species richness treatments (black lines in Figure 1a and b) or within species richness treatments (coloured lines in Figure 1a and b).

Second, we hypothesise that reducing seed dispersal will increase the importance of the functiondominance correlation for BEF relationships, because seed dispersal decreases the relative abundance of the dominant species in our simulations. For example, if the function-dominance correlation is positive, lower relative abundance of the dominant species resulting from seed dispersal will lead to a lower community functioning (Leibold et al., 2017). Thus, when the community is isolated from seed dispersal, relative abundance of the dominant species will increase, leading to increased ecosystem functioning while reducing realised diversity.

Consistent with our hypotheses, our results show that when the dominant species also contribute disproportionally to ecosystem functioning (i.e., positive functiondominance correlation), BEF relationships tend to be positive across communities with different species richness treatments and negative across communities within the same species richness treatment (i.e., a "positive counter-gradient'). Alternatively, BEF relationships tend to be weak or lead to a 'negative counter-gradient', when the function-dominance correlation is weak or negative, respectively. Further, the importance of the functiondominance correlation for BEF relationships across communities is higher in the absence of external seed input. Thus, the function-dominance correlation provides an 
ecologically grounded and empirically tractable metric that appears to explain much of the context dependence observed across BEF relationships. This work therefore has major implications for how to apply BEF research to the problem of biodiversity change. In particular, if $\mathrm{BEF}$ relationships are determined by the function-dominance correlation, then changes in the identity of species in the local community, as is occurring in many communities worldwide (Blowes et al., 2019; Dornelas et al., 2014), may have larger impacts on ecosystem functioning than declines in species richness per se.

\section{MATERIALS AND METHODS}

\section{Model descriptions}

We included six published plant community models that cover a variety of ecosystems and model types, ranging from forests to succulent plants and from systems of differential equations to spatially explicit, individual-based models (Table 1). These capture key elements of their target systems and have been extensively analysed and documented in published literature (Clark et al., 2018; Maréchaux \& Chave, 2017; May et al., 2009; Reineking et al., 2006; Rüger et al., 2020; Turnbull et al., 2013; Weiss et al., 2014). They support realistic levels of biodiversity, and the mechanisms driving coexistence are well understood.

Grass 1 (Clark et al., 2018) explores a trade-off between species' abilities to take up and retain resources versus to pre-empt other species from accessing resources. The model is designed to portray dynamics in a Minnesota tallgrass prairie and was parameterised from observations of three plant traits measured in experimental monocultures. Model dynamics are deterministic and allow for an arbitrarily large number of species to stably coexist, provided that their traits all fall within the correct regions of the trade-off space.

Grass 2 (Turnbull et al., 2013) is also designed to mimic dynamics in grassland plant communities and focuses on a classic trade-off between species relative growth rate and carrying capacity. The model explicitly considers effects of seasonal cycles. Fast-growing species can persist because they can rapidly exploit resources early in the growing season, before slower growing species become dominant. Again, this model is deterministic and allows arbitrarily large numbers of species to stably coexist.

Grass 3 (May et al., 2009; Weiss et al., 2014) explores trade-offs between asymmetric competition for light and susceptibility to grazing within central European managed grasslands. Competition is individual-based and spatially explicit. Given adequate belowground resources, larger, faster growing species dominate competition for light but are more vulnerable to grazing than their shorter, more stress-tolerant competitors. The resulting trade-off equalises fitness among competing

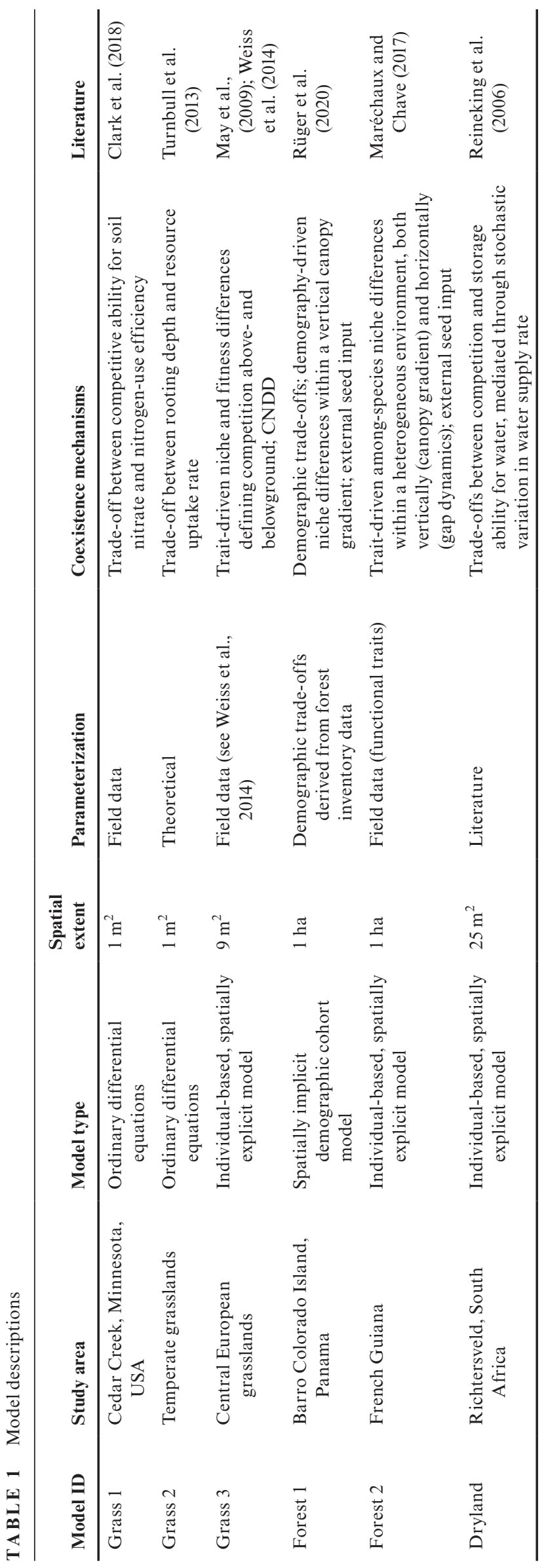


species, and stable coexistence is realised through conspecific negative density dependence that reduces the fitness of individuals when surrounded by conspecific neighbours.

Forest 1 (Rüger et al., 2020) is designed to simulate dynamics of a diverse tropical rainforest at Barro Colorado Island, Panama, based on species demographic rates (growth, survival and recruitment). It accounts for height-structured competition for light by distinguishing four canopy layers. Canopy gaps are filled by the tallest trees from lower canopy layers, regardless of their horizontal position (perfect plasticity approximation; Purves et al., 2008). Tree species fall along two demographic trade-offs: a growth-survival trade-off and a stature-recruitment trade-off (Rüger et al., 2018). Here, as in Rüger et al., (2020), the model is deterministic, and stable coexistence within local communities relies on external seed inflow.

Forest 2 (Maréchaux \& Chave, 2017) is an individualbased and spatially explicit model of tropical forest dynamics. It uses species-specific functional traits to parameterise tree physiological function and demographic processes, according to relationships and trade-offs from the literature. Individual trees compete for light within a three-dimensional grid ( $1 \mathrm{~m}^{3}$ voxels), in which tree death and gap formation create horizontal and vertical heterogeneity in light availability. Seed dispersal is spatially explicit and includes both local sources and external seed inflow. Here, we used a model version without explicit conspecific negative density dependence, so that stable coexistence relies on external seed inflow.

Dryland (Reineking et al., 2006) is an individualbased, stochastic model based on allocation trade-offs and environmental heterogeneity. The model is parameterised for succulent communities in the Richtersveld, South Africa (see Appendix S1: Model preparation). Plants compete for water, and biomass allocation to leaves, roots, water storage and seeds affects plant growth, survival and reproduction. At high water supply rates, species not investing in water storage outcompete species investing in storage, which in turn persist longer under drought. Coexistence is partially maintained by spatiotemporal heterogeneity in water supply. In the present study, higher levels of local diversity were maintained via seed inflow.

\section{Experimental design}

For each model, a set of 64 species was selected by sampling a functionally diverse assemblage from its species pool. Depending on the model, this was achieved through either sampling species from the underlying trade-off surface (Grass 1, Grass 2 and Dryland) or by running $k$-means clustering $(k=64)$ on the species pool (Grass 3 , Forest 1 and Forest 2). For each model, we implemented an experimental design typical of $\mathrm{BEF}$ experiments (sensu Roscher et al., 2004; Tilman et al., 1996), including seven planted species richness treatments $(1,2,4,8,16$, 32 or 64 species) with 64 replicates each (except for the 64-species treatment with only one replicate). The onespecies treatment consisted of monocultures of each of the 64 species, and the 2-32-species treatments were implemented by randomly sampling (without replacement) from the 64-species pool.

For each model, the $385\left(6^{*} 64+1\right)$ experimental communities were initialised with equal abundances of seeds or seedlings for each planted species (depending on each model's default settings) and run until stable abundance distributions were achieved (hereafter 'equilibrium'; see Appendix S1: Experimental design). Thus, due to their slower dynamics, forest models were run significantly longer than grassland and succulent models.

During this initial stage, seed inflow from the initial species pool took place (with seed inflow). Seed inflow for each species was constant and corresponded to average internal seed production across all equilibrium monocultures, divided by the number of species. This implementation generates equal numbers of saplings (forest models) or equal seed biomass (grassland/dryland models) per species per year and therefore buoys abundances of poorly performing species. To explore the effect of isolating communities from their respective metacommunities, in a second stage of the same duration, seed inflow was stopped (without seed inflow). We measured diversity and ecosystem functioning on the last time steps of each stage.

\section{BEF relationships within models}

For the results presented here, we use Shannon diversity to quantify community diversity. We do so because Shannon diversity incorporates information about both richness and evenness, and in several models, species abundances decline to very low levels rather than to zero (i.e., 'asymptotic' extinction). Thus, when species became functionally extinct, realised species richness remained unchanged. Note, however, that when analysed in terms of richness, our results are qualitatively similar (see Appendix S2). We also present results for two related ecosystem properties: (1) aboveground biomass (main results) and (2) net primary productivity (Appendix S3; results are identical to biomass for grassland models but not for dryland and forest models). To enable comparison between models with very different amounts of total biomass, we scaled the community biomass across all simulated communities to fall between 0 and 100 .

Our analysis consisted of two steps. In the first step, for each plant community model and seed inflow stage, we fit a Bayesian linear regression between realised Shannon diversity and biomass across planted species richness levels to estimate the across species richness treatment BEF slope (black line in Figure 1; see Appendix S1: Statistical methods). In the second step, we 
fit independent Bayesian linear regressions within each planted species richness level to quantify within species richness treatment $\mathrm{BEF}$ slopes (coloured lines in Figure 1) for each plant community model and seed inflow stage (see Appendix S1: Statistical methods).

Regressions were fit using the Hamiltonian Monte Carlo (HMC) sampler Stan (Carpenter et al., 2017) through the 'brms' package (Bürkner, 2017) in R (R Core Team, 2019) using four chains, 2000 iterations (1000 as warm up), and Gaussian distributions for all models. We used weakly regularising default priors, and inspection of the HMC chains for each model showed excellent convergence, with R-hat values of 1.0 for all estimates. We used posterior predictive checks to visually inspect how well the statistical models reproduced the data (see Appendix S4).

\section{Comparison across models}

We quantified the function-dominance correlation for each seed inflow stage separately. To do this, we bootstrapped species' mixture biomasses $(n=2500)$ using the 32-species mixtures. Each bootstrap contained 2048 species (32 species per mixture $\times 64$ replicates) selected with replacement. We then calculated the Pearson's correlation between species' biomasses in monoculture ('function') and their respective mixture biomasses ('dominance'). Note that like the 'selection effect' of Loreau and Hector (2001), our correlation coefficient effectively summarises overall effects of dominance on yield in mixture - that is, it tests whether highly functioning species in monoculture also tend to be highly functioning in mixture. We use this metric, rather than the classic Loreau and Hector metric, both for simplicity, and to avoid issues related to low or zero monoculture biomass that can complicate the classic Loreau and Hector metric (Clark et al., 2019).

We focused on the 32-species communities because they encompass the highest initial diversity of any treatment level beyond the single replicated 64-species treatment. We then drew 2500 samples from the posterior distributions of the within-treatment and across-treatment BEF slopes of each model and regressed them against the functiondominance correlations. Since both metrics are estimated and thus incorporate error, we used Standard Major Axis regression (lmodel2; Legendre, 2018).

\section{RESULTS}

\section{Communities with seed inflow}

In communities with seed inflow, community biomass was positively correlated with realised Shannon diversity across species richness treatments in five of the six models (all except Forest 2). The most pronounced positive relationships emerged from Grass 1, Grass 2 and Forest 1 (Figure 2). Within species richness treatments, the slope of the relationship between realised diversity and biomass was negative in four out of the six models. This pattern was most pronounced in Grass 1 and Forest 2. In Grass 2 and Forest 1, the slope of the relationship between realised diversity and biomass was negative within communities with low species richness and became positive with increasing species richness. In Grass 3 and Dryland, the slope of the relationship between realised diversity and biomass tended to be positive within species richness treatments.

Consistent with our hypothesis, the effect of realised diversity on community biomass was more positive across species richness treatments (Figure 3) and more negative within species richness treatments (Figure 4) in models where the function-dominance correlation was positive (cf. Figure 1). This relationship also emerged when using realised species richness as a measure of diversity rather than Shannon diversity (Appendix S2) and productivity as a measure of ecosystem functioning (Appendix S3).

\section{Communities without seed inflow}

After local communities were isolated from their metacommunity (by eliminating seed inflow), there was no consistent pattern in how the slope of the relationship between realised diversity and biomass changed across species richness treatments (Figure 2). However, within communities of the same species richness treatment, the slope of the relationship between realised diversity and biomass often became more positive than in simulations with seed inflow, for example, switching from negative to positive (Grass 2 and Forest 2), becoming less negative (Grass 1) or becoming more positive (Dryland).

Eliminating seed inflow did not substantially alter the function-dominance correlation, except for Forest 2 , where this correlation changed from positive to negative (see Appendix S4). Consequently, the overall relationship between the function-dominance correlation and the slope of the relationship between realised diversity and biomass across species richness treatments became even more strongly positive (Figure 3 ). In contrast, within species richness treatments, the relationship between the function-dominance correlation and the slope of the relationship between realised diversity and biomass tended to become weaker (Figure 4). Similar results were obtained using productivity (rather than biomass) as the measure of ecosystem functioning (Appendix S3) or using realised species richness (rather than realised Shannon diversity) as the measure of community diversity (Appendix S2). 
Grass1

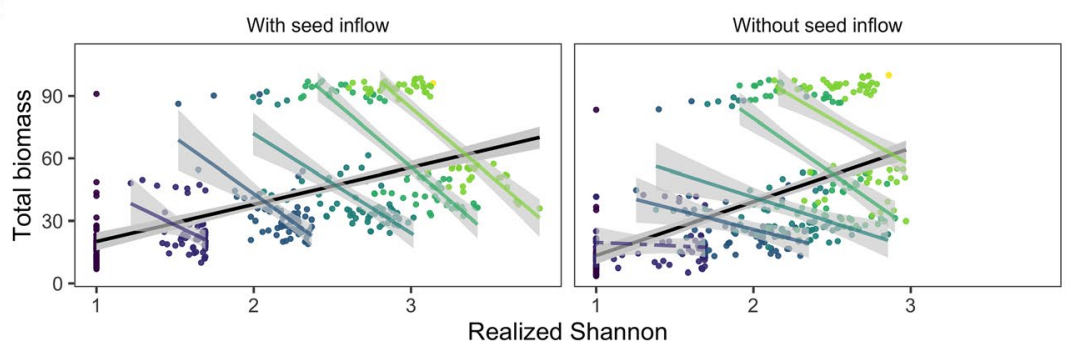

Grass2

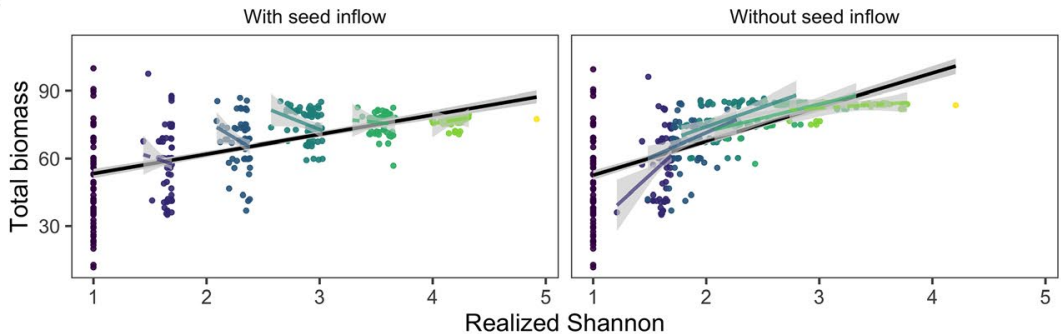

Grass3

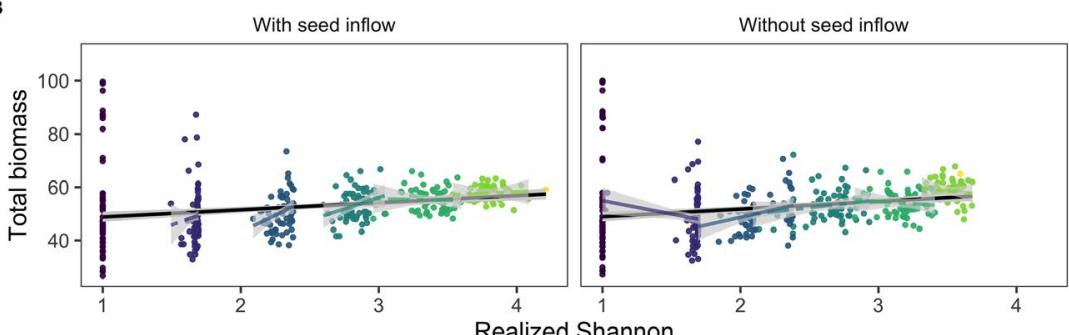

Planted species

richness

Forest1

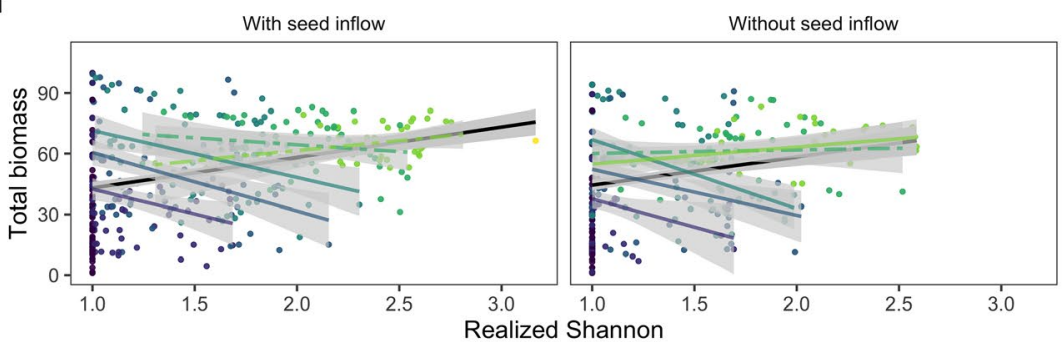

- 1

- 2

- 4

- 8
- 16

32
$-\quad 64$

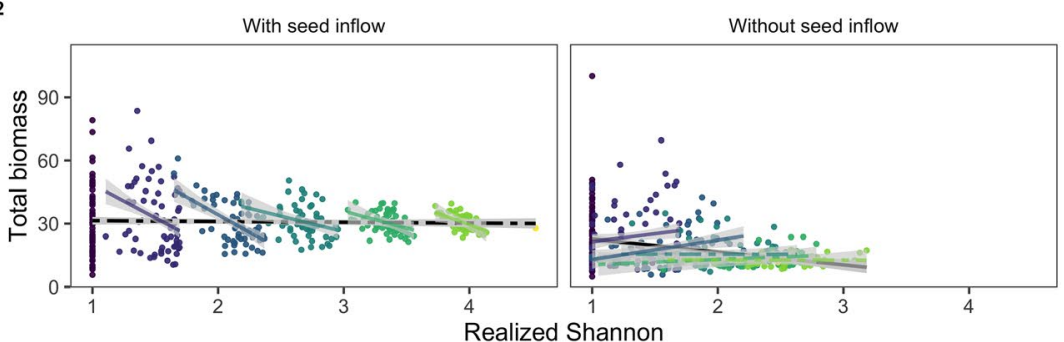

Dryland

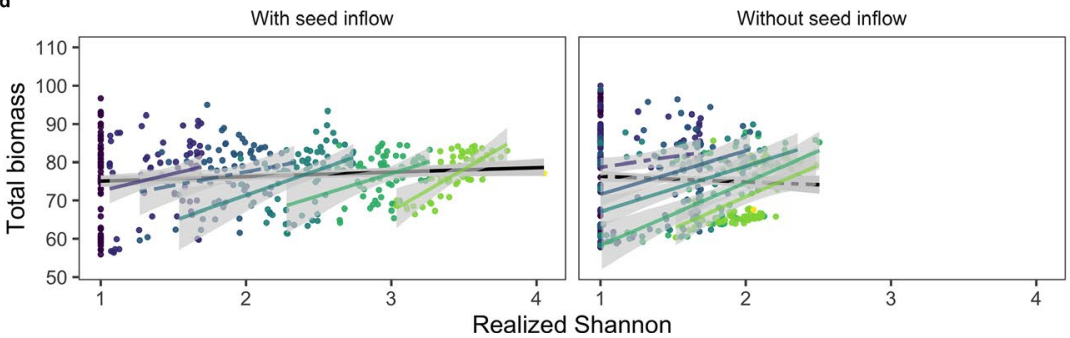

F I G U R E 2 The relationship between realised Shannon diversity and total community biomass for six plant community models. Points represent individual plant communities. Coloured lines refer to the relationships within species richness treatments, while the black lines refer to the relationship across species richness treatments. Ribbons represent the $95 \%$ credibility intervals of the model fits. Significant relationships ( $95 \%$ CI does not include 0) are shown with solid lines. Insignificant relationships are shown with dashed lines 


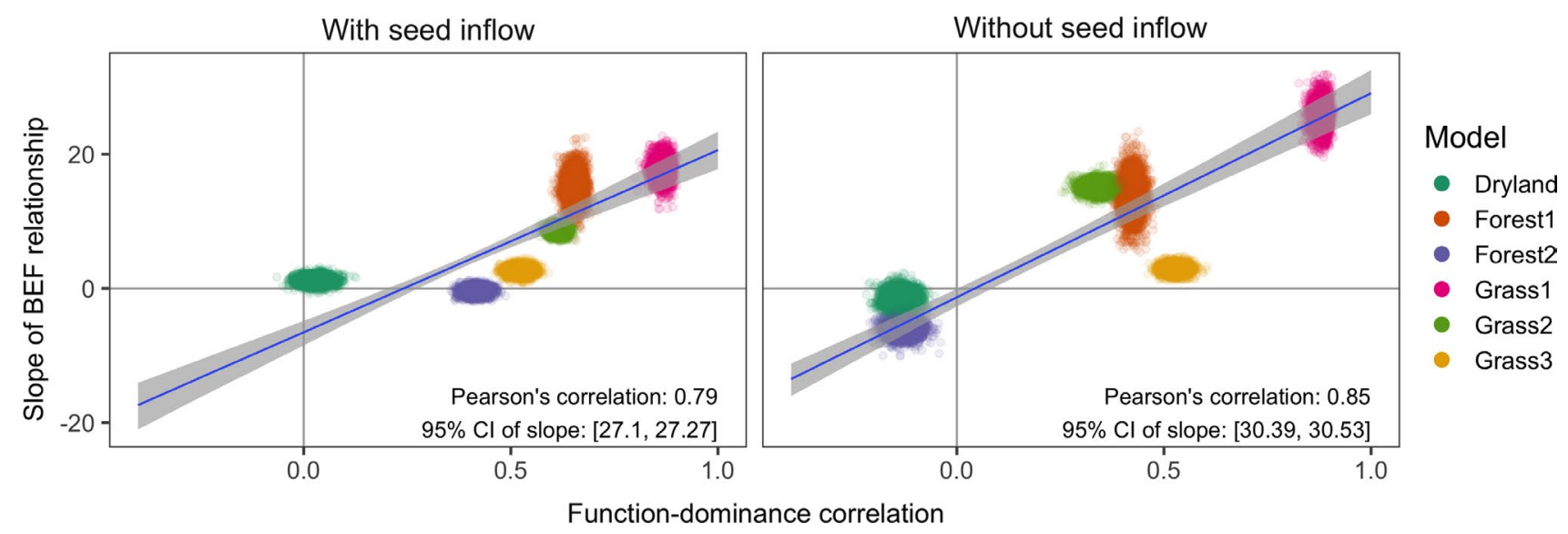

F I G U R E 3 The relationship between the function-dominance correlation and the slope of the BEF relationship across species richness treatments for six plant community models. Standard major axis regressions were run on each bootstrapped dataset $(n=2500)$, which each contained one function-dominance correlation paired with one posterior sample of the BEF slope per model. Ninety-five per cent confidence intervals for the mean where derived through nonparametric bootstrapping of the slope parameter $(n=1000)$

\section{DISCUSSION}

Biodiversity experiments have convincingly demonstrated the importance of biodiversity for ecosystem functioning. However, applying these findings to naturally assembled systems has proven challenging (van der Plas, 2019). We show that the sign and magnitude of BEF relationships both across species richness treatments (as traditionally reported for BEF experiments) and within species richness treatments can be predicted by the correlation between species' contribution to functioning and species' dominance in mixture (the 'function-dominance correlation'). When dominant species have a high capacity to provide ecosystem functioning, realised diversity and functioning are positively related across species richness treatments but negatively related within species richness treatments. Further, removing seed inflow strengthens the explanatory power of the function-dominance correlation across species richness treatments but weakens it within them. Importantly, our model intercomparison shows that these results are consistent for both biomass and net primary productivity, and across six different models that have been shown to accurately represent dynamics of grasslands, tropical forests and a dryland succulent community.

\section{The function-dominance correlation mediates BEF relationships}

Relationships between realised Shannon diversity and biomass were positive across species richness treatments for five out of six models. This result is consistent with many biodiversity experiments (reviewed by Tilman et al., 2014). However, relationships between realised diversity and biomass were often negative within species richness treatments, especially in models that had the most positive relationships across species richness treatments (i.e., Grass 1, Grass 2 and Forest 1). This negative
BEF relationship within species richness treatments is also consistent with results from the Jena Experiment (Leibold et al., 2017; Rychtecká et al., 2014) but has not, to our knowledge, been tested elsewhere.

Our results show that this 'counter-gradient' can be explained by the function-dominance correlation. Where this correlation is strong and positive (Grass 1, Grass 2 and Forest 1), BEF relationships across species richness treatments were most positive, and BEF relationships within species richness treatments were most negative. A likely explanation is that communities with more species are more likely to include dominant species that produce high levels of ecosystem functioning through a 'sampling effect' (Hooper et al., 2005; Huston, 1997). However, within species richness treatments, these same dominant and high-functioning species tend to displace poorly performing species, potentially driving the negative relationship between functioning and realised diversity. Conversely, where the function-dominance correlation is weak (Grass 3, Forest 2 and Dryland), the relationship between realised diversity and biomass is weak or not significant, both across species richness treatments and within them.

This clear link between the function-dominance correlation and BEF relationships emerged despite the array of coexistence mechanisms and systems in our models. Interestingly, the strength of the functiondominance correlation was not related to mechanism type, that is, resource partitioning (Grass 1, Grass 2 and Dryland), seed inflow (Forest 1 and Forest 2) or conspecific negative density dependence (Grass 3). However, strong local coexistence mechanisms like resource partitioning (Dryland) and conspecific negative density dependence (Grass 3) increased the slope of positive relationships between realised diversity and ecosystem functioning within species richness treatments. Grass 3, for example, is spatially explicit and incorporates conspecific negative density dependence. 


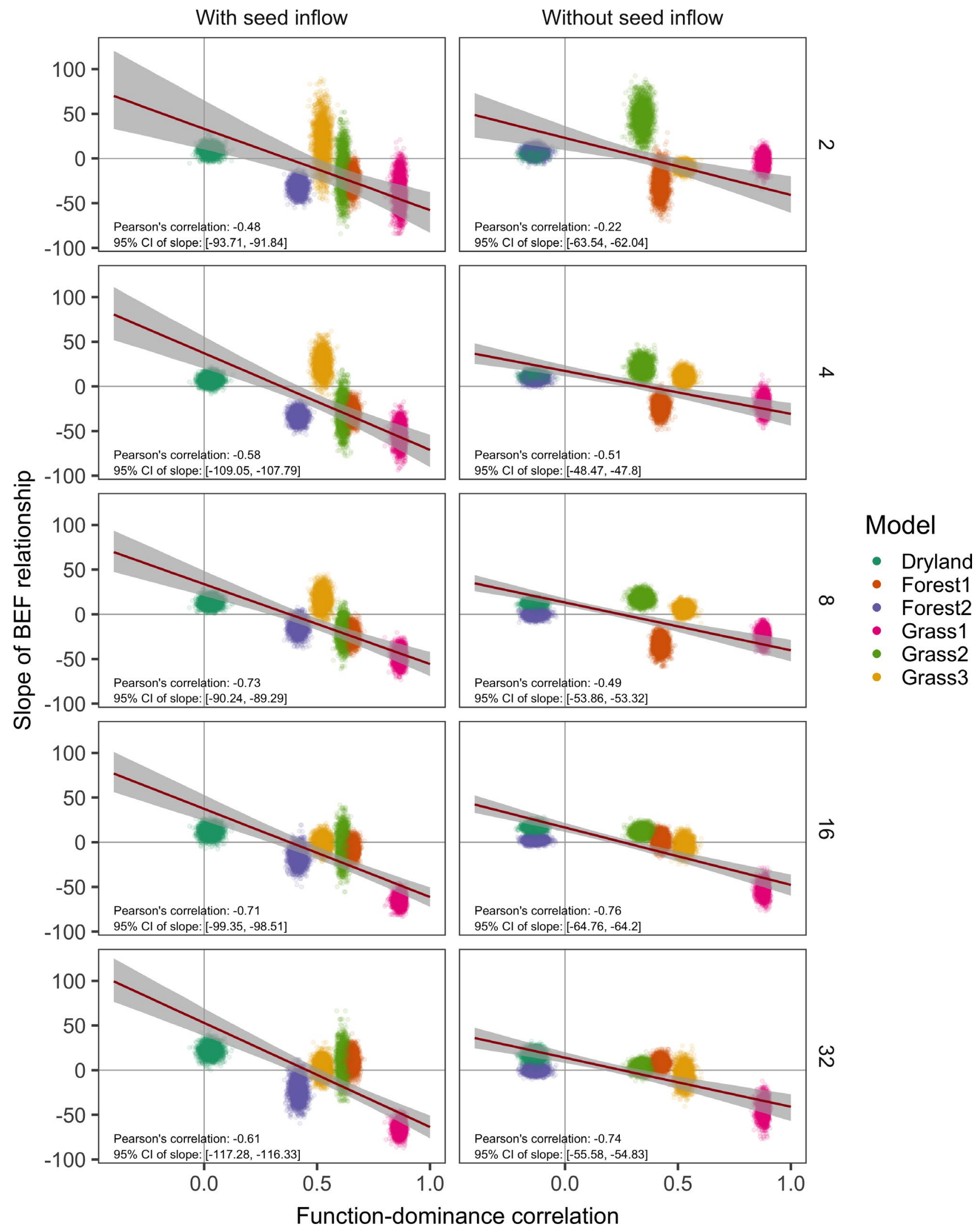

F I G U R E 4 The relationship between the function-dominance correlation and the slope of the BEF relationships within species richness treatments for six plant community models. Standard major axis regressions were run on each bootstrapped dataset $(n=2500)$, which each contained one function-dominance correlation paired with one posterior sample of the BEF slope per model and species richness treatment. Intervals indicate $95 \%$ confidence of the mean, derived through nonparametric bootstrapping of the slope parameter $(n=1000)$ 
Individuals surrounded by conspecifics perform more poorly than individuals surrounded by heterospecifics (May et al., 2009). Because individuals are more likely to be surrounded by heterospecifics in communities with higher realised diversity, these more diverse communities are also higher functioning. In higher species richness treatments, effects of negative density dependence are weak regardless of realised diversity, and these effects disappear. Similarly, in Forest 1, BEF relationships within species richness treatments are negative at low species richness but become positive at high species richness. In this model, more diverse communities are likely to include several species of similar competitive ability that are able to coexist. For example, communities of 'tall' versus 'slow' species coexist because tall species maximise biomass in upper canopy layers while slow species maximise biomass in lower layers. Thus, at higher species richness levels, species with these strategies partition the vertical canopy gradient, leading to positive BEF relationships within species richness treatments. In contrast, only one of these strategies is likely to be represented in low species richness treatments, in which case the highest biomass occurs when one of these strategies dominates resulting in low realised diversity.

Unlike the function-dominance correlation, the specific slope and sign of the relationship between realised diversity and biomass varied with model structure both between species richness treatments and within species richness treatments. For example, the two tropical forest models show differing results. However, across model types, study systems and community assembly mechanisms, we were able to identify a common pattern: the link between the function-dominance correlation and the strength and direction of BEF relationships. Thus, we expect that the function-dominance correlation is relevant for understanding variation in the sign and magnitude of BEF relationships across a wide variety of systems.

\section{The effect of removing seed inflow}

One benefit of our modelling approach is our ability to eliminate external dispersal (inflow). In BEF experiments, although plots are weeded, it is usually not possible to distinguish whether new recruits of planted species result from seeding treatments, dispersal from within the plot or external seed dispersal. Thus, it is impossible to fully isolate effects of local interactions from external metacommunity processes. Although external seed inflow is thought to influence BEF relationships (Hooper et al., 2005; Roscher et al., 2004), we found that completely removing seed inflow had little effect on BEF relationships observed across species richness treatments, which are the most commonly reported BEF relationships in the literature.
However, within species richness treatments, the relationship between realised diversity and biomass often became more positive when seed inflow stopped (Grass 1, Grass 2, Forest 1, Forest 2 and Dryland). For example, in Grass 2, the slope of the relationship between realised diversity and biomass changed from negative (with seed inflow) to positive (without seed inflow) within species richness treatments. In this model, species are dominant in mixture by having either a high carrying capacity or a high growth rate (Turnbull et al., 2013). With seed inflow, low-biomass species with high growth rates temporarily prevent their slower competitors from accessing soil resources. Consequently, higher functioning, slower growing species are unable to reach maximum size. Without seed inflow, these high growth rate-low functioning species decrease in relative abundance, and the remaining species are better able to utilise available resources. These processes combined result in a positive relationship between realised diversity and biomass within species richness treatments.

Although eliminating seed inflow had noticeable effects on BEF relationships both across and within species richness treatments, function-dominance correlations remained largely unchanged with one exception. For Forest 2, the slope of the function-dominance correlation changed from positive (with seed inflow) to negative (without seed inflow). In this model, small, low-biomass species disproportionately benefited from removing seed inflow because they reach their reproductive size more rapidly than tall, high-biomass species. Without seed inflow, these low-biomass species could colonise more empty sites and reach a higher biomass in mixture than tall species. This leads to a change in the function-dominance correlation from positive with seed inflow to slightly negative without seed inflow, which in turn caused a reversal of the counter-gradient (negative across species richness treatments and positive within species richness treatments without seed inflow). This reversal reinforced the relationship between the functiondominance correlation and the slope of the relationship between realised diversity and biomass across species richness treatments. This result, along with the Dryland model without seed inflow, is the only example that we know of a negative counter-gradient: a negative BEF relationship across species richness treatments but positive BEF relationships within species richness treatments.

Seed inflow in our models is limited to the original species pool and assumes constant, uniform seed input across species. While this approach is not realistic, our results are consistent with findings from a recent metaanalysis of seed addition experiments (Ladouceur et al., 2020) which found that when dispersal limitation was alleviated by seed addition, species richness increased (also reviewed by Myers \& Harms, 2009), while biomass was relatively unaffected. Similarly, in our models, communities generally had higher realised diversity with seed inflow than without it, with biomass remaining 
largely unaffected relative to changes in Shannon diversity (Appendix S5). Realised species richness was bolstered by seed inflow more than realised Shannon diversity, leading to a larger relative increase in the across-treatment slope once seed inflow was removed (Appendix S2). This strong response emerged because seed inflow was uniformly distributed and thus kept realised richness artificially high and reduced the importance of local competitive dynamics in driving communities' biomass and productivity.

\section{Applying our results to other functions and applications}

Here, we focus on relationships between realised diversity and aboveground biomass/productivity. Aboveground biomass and productivity are good indicators for many other functions and services, such as root biomass, carbon storage/sequestration, harvestable volume for forests and ecosystem stability (Allan et al., 2013; Ratcliffe et al., 2017). We therefore expect that our results will hold for this set of functions. However, other functions such as aboveground and belowground decomposition, nutrient cycling, microbial biomass or resistance to climate extremes are not easily predicted by biomass or productivity. Although we would not expect the biomass-based function-dominance correlation to be informative for these functions, it may be that function-dominance correlations that are based on these other functions or related functions could still prove to be useful predictors. For example, in microbial systems, if a species comprises a large amount of microbial biomass in monoculture and also plays a dominant role in contributing a large amount of microbial biomass in mixture (positive function-dominance correlation for microbial biomass), then we would predict that the relationship between realised diversity and microbial biomass across species richness treatments would be strongly positive.

Function-dominance correlations may be an effective ecosystem assessment tool that could be adopted by applied ecologists interested in maintaining or restoring ecosystem health. Assessing function-dominance relationships with respect to species losses and gains may allow better prioritisation of management actions for conservation and more function-driven restoration (Ladouceur et al., 2021). Species loss and gain is commonly observed in many conservation areas, particularly those that lie within successional habitats such as old fields (Bourgeois et al., 2016; Walker et al., 2007). The function-dominance correlation, rather than species identity per se, may serve as an indicator of whether assisted community assembly (e.g., through replanting or re-seeding) would be effective at restoring additional ecosystem functioning (Isbell et al., 2019; Ladouceur et al., 2020). The function-dominance correlation may serve as a community profile tool that allows assessment of ecosystem health and the success of management, conservation or restoration (sensu Matthews \& Whittaker, 2015).

\section{CONCLUSIONS}

Global biodiversity loss and local and regional biodiversity change are among humanity's most pressing concerns. The current consensus is that this change is likely to have devastating consequences on ecosystem functioning. However, our results suggest that diversity change will have the strongest impact on ecosystem functioning when dominant species provide the most function. If this is also found to be true in experiments and naturally assembled systems, it has important implications for biodiversityecosystem functioning research. Loss of - or change in-biodiversity may have smaller or larger effects on ecosystem functioning than currently predicted, depending on the species affected. If species that are lost are dominant and high functioning, we expect that their loss will cause declines in ecosystem functioning unless they are replaced by species that perform similarly well. Alternatively, if the species lost dominated the community while contributing little to functioning (e.g., by taking up space and pre-empting the establishment of higher-biomass species), the effect of biodiversity loss on ecosystem functioning may be positive even, while other effects of losing these species could be negative. For example, recent research indicates that tall, high-biomass tree species may be more prone to extinction future climate conditions than smaller or low-biomass species (McDowell et al., 2020), with negative consequences for ecosystem functioning (Aubry-Kientz et al., 2019; Rüger et al., 2020). Our results suggest that within these systems, ecosystem functioning may be likely to decline even if it is not reliant on species richness per se. Our results also suggest that isolation from seed sources may amplify the functional role of dominant species. This is particularly relevant in the context of land-use change, and the habitat fragmentation that follows it, which is currently regarded as the largest cause of biodiversity change globally (Intergovernmental Science-Policy Platform on Biodiversity \& Ecosystem Services, 2019). By comparing the outputs from six well-understood models that span different ecosystem types and community assembly mechanisms, we were able to identify an emergent community metric - the function-dominance correlation-that drives variation in BEF relationships. This synthesis provides key information about how changes in community composition rather than biodiversity loss per se are likely to influence ecosystem functioning under global change. 


\section{ACKNOWLEDGEMENTS}

This paper is a product of the SimNet workshop funded by the FlexPool initiative (Grant 34600966) - the internal funding mechanism of the German Centre for Integrative Biodiversity Research (iDiv) Halle-Jena-Leipzig, a research centre of the German Research Foundation (DFG-FZT 118, 202548816). We are grateful to Volker Grimm and Jonathan Chase for their helpful comments throughout the planning and execution of this project. KEB was funded by the iDiv FlexPool initiative (Grant 34600900). JL acknowledges sabbatical fellowship support from sDiv, the Synthesis Centre of iDiv (DFGFZT 118, 202548816). IM acknowledges funding from 'Investissement d'Avenir' managed by Agence National de la Recherche (CEBA, ref. ANR-10-LABX-25-01; TULIP, ref. ANR-10-LABX-0041). BR acknowledges funding from EU FP7 ERA-NET Sumforest (Grant ANR-16SUMF-0002). NR acknowledges support by a research grant from Deutsche Forschungsgemeinschaft DFG (RU 1536/3-1). MC and NR were supported by the iDiv flexpool initiative (Grants 34600967 and 34600970). Open Access funding enabled and organized by Projekt DEAL.

\section{AUTHOR CONTRIBUTIONS}

This study was devised as a product of a collaborative workshop attended by all authors. MC, NR, ATC, IM, FM, BR and LAT designed the initial model intercomparison project with feedback from other authors. MC, ATC, IM, CF and BR performed modelling experiments on individual models and provided data and feedback to MC. MC conducted model intercomparison analyses with input from NR, KEB and ATC. KEB, MC, NR and ATC wrote and revised initial drafts of the manuscript. All authors contributed to the revision of the manuscript.

\section{PEER REVIEW}

The peer review history for this article is available at https://publons.com/publon/10.1111/ele.13776.

\section{OPEN RESEARCH BADGES}

\section{(AI) 18}

This article has earned Open Data and Open Materials badges. Data and materials are available at: https://doi. org/10.5281/zenodo.4658931

\section{DATA AVAILABILITY STATEMENT}

All data, analyses and code for statistical analyses will be uploaded to a public repository upon acceptance of this paper for publication. All models are previously published and archived.

\section{ORCID}

Michael S. Crawford (D) https://orcid. org/0000-0003-1282-400X

Kathryn E. Barry (1) https://orcid. org/0000-0001-6893-6479
Emma Ladouceur (10) https://orcid.

org/0000-0002-4943-4358

Lindsay A. Turnbull (1) https://orcid.

org/0000-0002-8035-2879

Nadja Rüger (1) https://orcid.org/0000-0003-2371-4172

\section{REFERENCES}

Allan, E., Weisser, W.W., Fischer, M., Schulze, E.-D., Weigelt, A., Roscher, C. et al. (2013) A comparison of the strength of biodiversity effects across multiple functions. Oecologia, 173, 223-237.

Aubry-Kientz, M., Rossi, V., Cornu, G., Wagner, F. \& Hérault, B. (2019) Temperature rising would slow down tropical forest dynamic in the Guiana Shield. Scientific Reports, 9, 10235.

Barry, K.E., de Kroon, H., Dietrich, P., Stanley Harpole, W., Roeder, A., Schmid, B. et al. (2019a) Linking local species coexistence to ecosystem functioning: a conceptual framework from ecological first principles in grassland ecosystems. In: Eisenhauer, N., Bohan, D.A. \& Dumbrell, A.J. (Eds.) Advances in Ecological Research, 61, Amsterdam: Elsevier, pp. 265-296.

Barry, K.E., Mommer, L., van Ruijven, J., Wirth, C., Wright, A.J., Bai, Y. et al. (2019b) The Future of complementarity: disentangling causes from consequences. Trends in Ecology \& Evolution, 34, 167-180.

Blowes, S.A., Supp, S.R., Antão, L.H., Bates, A., Bruelheide, H., Chase, J.M. et al. (2019) The geography of biodiversity change in marine and terrestrial assemblages. Science, 366, 339-345.

Bohn, F.J. \& Huth, A. (2017) The importance of forest structure to biodiversity-productivity relationships. Royal Society Open Science, 4, 160521.

Bourgeois, B., Vanasse, A., González, E., Andersen, R. \& Poulin, M. (2016) Threshold dynamics in plant succession after tree planting in agricultural riparian zones. Journal of Applied Ecology, 53, 1704-1713. https://doi.org/10.1111/1365-2664.12675

Bürkner, P.-C. (2017) brms: an R package for bayesian multilevel models using stan. Journal of Statistical Software, 80, 1-28.

Carpenter, B., Gelman, A., Hoffman, M.D., Lee, D., Goodrich, B., Betancourt, M. et al. (2017) Stan: a probabilistic programming language. Journal of Statistical Software, 76.

Clark, A.T., Barry, K.E., Roscher, C., Buchmann, T., Loreau, M. \& Harpole, W.S. (2019) How to estimate complementarity and selection effects from an incomplete sample of species. Methods in Ecology and Evolution, 10, 2141-2152.

Clark, A.T., Lehman, C. \& Tilman, D. (2018) Identifying mechanisms that structure ecological communities by snapping model parameters to empirically observed tradeoffs. Ecology Letters, 21, 494-505.

Dornelas, M., Gotelli, N.j., McGill, B., Shimadzu, H., Moyes, F., Sievers, C. et al. (2014) Assemblage time series reveal biodiversity change but not systematic loss. Science, 344, 296-299.

Duffy, J.E., Godwin, C.M. \& Cardinale, B.J. (2017) Biodiversity effects in the wild are common and as strong as key drivers of productivity. Nature, 549, 261-264.

Gonzalez, A., Germain, R.M., Srivastava, D.S., Filotas, E., Dee, L.E., Gravel, D. et al. (2020) Scaling-up biodiversity-ecosystem functioning research. Ecology Letters, 23, 757-776.

Gonzalez, A., Mouquet, N. \& Loreau, M. (2009) Biodiversity as spatial insurance: the effects of habitat fragmentation and dispersal on ecosystem functioning. In: Naeem, S., Bunker, D.E., Hector, A., Loreau, M. \& Perrings, C. (Eds.) Biodiversity, ecosystem functioning, and human wellbeing: an ecological and economic perspective. Oxford: Oxford University Press.

Guerrero-Ramírez, N.R., Craven, D., Reich, P.B., Ewel, J.J., Isbell, F., Koricheva, J. et al. (2017) Diversity-dependent temporal divergence of ecosystem functioning in experimental ecosystems. Nature Ecology \& Evolution, 1, 1639-1642. 
Holt, R.D. (2013) Species coexistence. In: Levin, S.A. (Ed.) Encyclopedia of biodiversity, 2nd edition. Waltham: Academic Press, pp. 667-678.

Holzwarth, F., Rüger, N. \& Wirth, C. (2015) Taking a closer look: disentangling effects of functional diversity on ecosystem functions with a trait-based model across hierarchy and time. Royal Society Open Science, 2, 140541.

Hooper, D.U., Chapin, F.S., Ewel, J.J., Hector, A., Inchausti, P., Lavorel, S. et al. (2005) Effects of biodiversity on ecosystem functioning: a consensus of current knowledge. Ecological Monographs, 75, 3-35.

Huston, M.A. (1997) Hidden treatments in ecological experiments: re-evaluating the ecosystem function of biodiversity. Oecologia, 110, 449-460.

Intergovernmental Science-Policy Platform on Biodiversity and Ecosystem Services (2019) Summary for policymakers of the global assessment report on biodiversity and ecosystem services. Population and Development Review, 45, 680-681.

Isbell, F., Tilman, D., Reich, P.B. \& Clark, A.T. (2019) Deficits of biodiversity and productivity linger a century after agricultural abandonment. Nature Ecology \& Evolution, 3, 1533-1538. https:// doi.org/10.1038/s41559-019-1012-1

Ladouceur, E., McGowan, J., Huber, P., Possingham, H., Scridel, D., van Klink, R. et al. (2021) An objective-based prioritization approach to improve trophic complexity through ecological restoration. BioRxiv. https://doi.org/10.1101/2021.03.09.434521

Ladouceur, E., Stanley Harpole, W., Blowes, S.A., Roscher, C., Auge, H., Seabloom, E.W. et al. (2020) Reducing dispersal limitation via seed addition increases species richness but not aboveground biomass. Ecology Letters, 23, 1442-1450.

Legendre, P. (2018) lmodel2: Model II Regression. R package version 1.7-3. https://CRAN.R-project.org/package=lmodel2

Leibold, M.A. \& Chase, J.M. (2018) Metacommunity ecology. 59, Princeton/Oxford: Princeton University Press.

Leibold, M.A., Chase, J.M. \& Ernest, S.K.M. (2017) Community assembly and the functioning of ecosystems: how metacommunity processes alter ecosystems attributes. Ecology, 98, 909-919.

Loreau, M. \& Hector, A. (2001) Partitioning selection and complementarity in biodiversity experiments. Nature, 412, 72-76.

Maréchaux, I. \& Chave, J. (2017) An individual-based forest model to jointly simulate carbon and tree diversity in Amazonia: description and applications. Ecological Monographs, 87, 632-664.

Matthews, T.J. \& Whittaker, R.J. (2015) Review: on the species abundance distribution in applied ecology and biodiversity management. Journal of Applied Ecology, 52, 443-454. https://doi. org/10.1111/1365-2664.12380

May, F., Grimm, V. \& Jeltsch, F. (2009) Reversed effects of grazing on plant diversity: the role of below-ground competition and size symmetry. Oikos, 118, 1830-1843.

McDowell, N.G., Allen, C.D., Anderson-Teixeira, K., Aukema, B.H., Bond-Lamberty, B., Chini, L. et al. (2020) Pervasive shifts in forest dynamics in a changing world. Science, 368, eaaz9463.

Meyer, S.T., Ptacnik, R., Hillebrand, H., Bessler, H., Buchmann, N., Ebeling, A. et al. (2018) Biodiversity-multifunctionality relationships depend on identity and number of measured functions. Nature Ecology \& Evolution, 2, 44-49.

Millenium Ecosystem Assessment (2005) Ecosystem and human wellbeing: synthesis. Washington, DC: Island Press.

Morin, X., Fahse, L., Scherer-Lorenzen, M. \& Bugmann, H. (2011) Tree species richness promotes productivity in temperate forests through strong complementarity between species. Ecology Letters, 14, 1211-1219.

Myers, J.A. \& Harms, K.E. (2009) Seed arrival, ecological filters, and plant species richness: a meta-analysis. Ecology Letters, 12, $1250-1260$.

Newbold, T., Hudson, L.N., Hill, S.L.L., Contu, S., Lysenko, I., Senior, R.A. et al. (2015) Global effects of land use on local terrestrial biodiversity. Nature, 520, 45-50.
Pereira, H.M., Leadley, P.W., Proença, V., Alkemade, R., Scharlemann, J.P.W., Fernandez-Manjarrés, J.F. et al. (2010) Scenarios for global biodiversity in the 21 st century. Science, 330, 1496-1501.

Pimm, S.1., Jenkins, C.n., Abell, R., Brooks, T.m., Gittleman, J.l., Joppa, L.n. et al. (2014) The biodiversity of species and their rates of extinction, distribution, and protection. Science, 344, 1246752.

Purves, D.W., Lichstein, J.W., Strigul, N. \& Pacala, S.W. (2008) Predicting and understanding forest dynamics using a simple tractable model. Proceedings of the National Academy of Sciences, 105, 17018-17022. https://doi.org/10.1073/pnas.08077 54105

R Core Team (2019) $R$ : A language and environment for statistical computing. Vienna, Austria: R Foundation for Statistical Computing.

Ratcliffe, S., Wirth, C., Jucker, T., van der Plas, F., Scherer-Lorenzen, M., Verheyen, K. et al. (2017) Biodiversity and ecosystem functioning relations in European forests depend on environmental context. Ecology Letters, 20, 1414-1426.

Reineking, B., Veste, M., Wissel, C. \& Huth, A. (2006) Environmental variability and allocation trade-offs maintain species diversity in a process-based model of succulent plant communities. Ecological Modelling, 199, 486-504.

Roscher, C., Schumacher, J., Baade, J., Wilcke, W., Gleixner, G., Weisser, W.W. et al. (2004) The role of biodiversity for element cycling and trophic interactions: an experimental approach in a grassland community. Basic and Applied Ecology, 5, 107-121.

Rüger, N., Comita, L.S., Condit, R., Purves, D., Rosenbaum, B., Visser, M.D. et al. (2018) Beyond the fast-slow continuum: demographic dimensions structuring a tropical tree community. Ecology Letters, 21, 1075-1084. https://doi.org/10.1111/ele.12974

Rüger, N., Condit, R., Dent, D.H., DeWalt, S.J., Hubbell, S.P., Lichstein, J.W. et al. (2020) Demographic trade-offs predict tropical forest dynamics. Science, 368, 165-168.

Rychtecká, T., Lanta, V., Weiterová, I. \& Lepš, J. (2014) Sown species richness and realized diversity can influence functioning of plant communities differently. Naturwissenschaften, 101, 637-644.

Shanafelt, D.W., Dieckmann, U., Jonas, M., Franklin, O., Loreau, M. \& Perrings, C. (2015) Biodiversity, productivity, and the spatial insurance hypothesis revisited. Journal of Theoretical Biology, 380, 426-435.

Simpson, E.H. (1951) The interpretation of interaction in contingency tables. Journal of the Royal Statistical Society: Series B (Methodological), 13, 238-241.

Thompson, P.L. \& Gonzalez, A. (2016) Ecosystem multifunctionality in metacommunities. Ecology, 97, 2867-2879.

Thompson, P.L., Guzman, L.M., Meester, L.D., Horváth, Z., Ptacnik, R., Vanschoenwinkel, B. et al. (2020) A process-based metacommunity framework linking local and regional scale community ecology. Ecology Letters, 23, 1314-1329.

Tilman, D., Isbell, F. \& Cowles, J.M. (2014) Biodiversity and ecosystem functioning. Annual Review of Ecology, Evolution, and Systematics, 45, 471-493.

Tilman, D., Wedin, D. \& Knops, J. (1996) Productivity and sustainability influenced by biodiversity in grassland ecosystems. Nature, 379, 718-720.

Tittensor, D.p., Walpole, M., Hill, S.1.1., Boyce, D.g., Britten, G.1., Burgess, N.d. et al. (2014) A mid-term analysis of progress toward international biodiversity targets. Science, 346, 241-244.

Turnbull, L.A., Levine, J.M., Loreau, M. \& Hector, A. (2013) Coexistence, niches and biodiversity effects on ecosystem functioning. Ecology Letters, 16, 116-127.

van der Plas, F. (2019) Biodiversity and ecosystem functioning in naturally assembled communities. Biological Reviews, 94, 1220-1245.

Walker, L.R., Walker, J. \& Hobbs, R.J. (Eds.) (2007) Linking restoration and ecological succession. Springer Series on Environmental Management. New York: Springer-Verlag. https://doi.org/10.1007/978-0-387-35303-6 
Weiss, L., Pfestorf, H., May, F., Körner, K., Boch, S., Fischer, M. et al. (2014) Grazing response patterns indicate isolation of semi-natural European grasslands. Oikos, 123, 599-612.

Wright, J.S. (2002) Plant diversity in tropical forests: a review of mechanisms of species coexistence. Oecologia, 130, 1-14.

\section{SUPPORTING INFORMATION}

Additional supporting information may be found online in the Supporting Information section.
How to cite this article: Crawford, M.S., Barry, K.E., Clark, A.T., Farrior, C.E., Hines, J., Ladouceur, E. et al. The function-dominance correlation drives the direction and strength of biodiversity-ecosystem functioning relationships.

Ecology Letters, 2021;00:1-14. https://doi. org/10.1111/ele.13776 